\title{
ETHANOL POTENTIATION OF CARBON TETRACHLORIDE HEPATOTOXICITY: POSSIBLE ROLE FOR THE IN VIVO INHIBITION OF ALDEHYDE DEHYDROGENASE
}

\author{
M. F. Kenel* $\dagger$ and A. P. KulKarNi \\ Toxicology Program, Department of Environmental and Industrial Health, School of Public Health, \\ University of Michigan, Ann Arbor, MI 48109-2029, U.S.A.
}

(Received 15 November 1984)

\begin{abstract}
A potentiation of $\mathrm{CCl}_{4}$-induced hepatotoxicity was observed in rats pretreated with ethanol $18 \mathrm{hr}$ prior to $\mathrm{CCl}_{4}$ exposure.

2. Hepatic microsomal aldehyde dehydrogenase $(A \mathrm{LDH})$ was significantly inhibited in animals sacrificed $1 \mathrm{hr}$ following the sequential exposure, however, no more so than in those animals receiving $\mathrm{CCl}_{4}$ alone.

3. The animals receiving ethanol alone had ALDH activity similar to vehicle treated controls.

4. Twenty-four hours following a potentiating dose of ethanol and $\mathrm{CCl}_{4}$ an 81 and $57 \%$ decline in $\mathrm{NAD}^{+}$-dependent microsomal and mitochondrial ALDH activity was observed, respectively.

5. Similar results were observed for microsomal and mitochondrial $\mathrm{NADP}^{+}$-dependent ALDH activity.

6. The decline in membrane-bound ALDH was greater in potentiated animals than in those receiving $\mathrm{CCl}_{4}$ alone.

7. A relatively smaller decline in cytosolic ALDH activity was observed in $\mathrm{CCl}_{4}$ treated rats with or without ethanol pre-exposure.

8. The data suggest that inhibition of membrane bound ALDH may be one of the major mechanisms of in vivo potentiation of $\mathrm{CCl}_{4}$-induced hepatotoxicity by ethanol.
\end{abstract}

\section{INTRODUCTION}

The ability of aliphatic alcohols to potentiate carbon tetrachloride $\left(\mathrm{CCl}_{4}\right)$ hepatotoxicity in experimental animals is well established (Cornish and Adefuin, 1967; Traiger and Plaa, 1971, 1974; Traiger and Bruckner, 1976; Cantillena et al., 1979). For ethanol, maximum potentiation occurs in rats when alcohol administration $(5 \mathrm{~g} / \mathrm{kg}$ p.o.) precedes the $\mathrm{CCl}_{4}$ treatment by $18 \mathrm{hr}$ (Traiger and Plaa, 1971). Despite numerous attempts to determine the mechanism of alcohol potentiation, the knowledge of specific potentiating events remain unknown.

Early investigations examined different alcohols or their metabolites as potentiators of $\mathrm{CCl}_{4}$ hepatoxicity (Traiger and Plaa, 1971, 1973; Traiger and Bruckner, 1976; Cantillena et al., 1979; Hewitt and Plaa, 1979; Dietz and Traiger, 1979; Curtis and Mehendale, 1980). Based on the observations that (a) pyrazole enhanced potentiation of ethanol- $\mathrm{CCl}_{4}$ hepatotoxicity (Traiger and Plaa, 1971), (b) ethanol concentrations in blood of $\mathrm{CCl}_{4}$-treated rats following an oral potentiating dose of ethanol were virtually undetectable (Traiger and Plaa, 1972) and (c) acetaldehyde administered intraperitoneally, $18 \mathrm{hr}$ prior to $\mathrm{CCl}_{4}$ failed to potentiate $\mathrm{CCl}_{4}$ hepatotoxicity

*Present address: International Research and Development Corporation, Mattawan, MI 49071, U.S.A.

$†$ The results reported in this paper are part of the Ph.D thesis submitted by M. F. Kenel to The University of Michigan. A brief account of this work was published in Toxicologist 2, 39 (1982).
(Traiger and Plaa, 1973), it was suggested that acetaldehyde does not play a significant role in ethanol$\mathrm{CCl}_{4}$ interactions. In contrast to these observations Strubelt et al. (1974) reported that $16 \mathrm{hr}$ following an oral dose of $5 \mathrm{~g} / \mathrm{kg}$ of ethanol, rat blood levels of ethanol were approximately 75 and $25 \%$ of peak blood levels in fed and fasted rats, respectively. Similarly, Sato et al. (1981) reported that $18 \mathrm{hr}$ following $5 \mathrm{~g} / \mathrm{kg}$ ethanol p.o. in the rat, relatively large amounts of ethanol were found in the blood $(0.8-3.9 \mathrm{mM})$ and in the liver $(1.1-4.8 \mathrm{mM})$. Therefore, the possibility exists that acetaldehyde is still being generated $18 \mathrm{hr}$ after ethanol treatment. Acetaldehyde was also shown to accumulate in mice receiving $\mathrm{CCl}_{4}$ and a subsequent dose of ethanol (Hjelle and Petersen, 1981). $\mathrm{CCl}_{4}$-dependent inhibition of hepatic cytosolic and mitochondrial aldehyde dehydrogenase (ALDH) was implicated to explain these observations. However, the possible inhibition of microsomal ALDH was not considered.

Besides acetaldehyde, the production of several other cytotoxic aldehydes during in vivo ethanol/ acetaldehyde- or $\mathrm{CCl}_{4}$-stimulated lipid peroxidation is well established (Ugazio et al., 1976; Valenzuela et $a l ., 1980$; Stege, 1982; Muller and Sies, 1982; Benedetti et al., 1980, 1982, 1984). These aldehydes are hepatotoxicants (Lieber et al., 1981; Bird et al., 1982; Benedetti et al., 1980, 1982, 1984), act as growth inhibitors (Chio and Tappel, 1969; Lieber, 1980; Dianzani, 1982) and impair the regenerating capacity of the liver. Since endoplasmic reticulum not only represents a major site of $\mathrm{CCl}_{4}$ activation (Recknagel, 1983), but also significantly contributes to the overall 


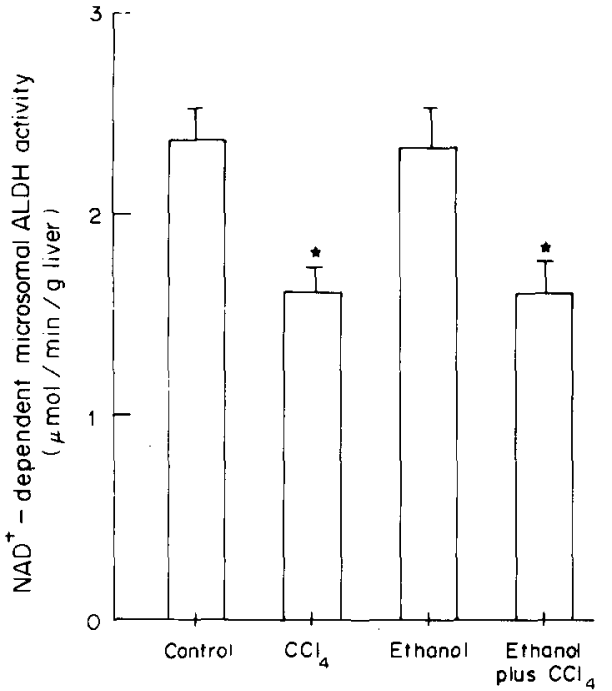

Fig. 1. Effect of $\mathrm{CCl}_{4}$, ethanol and ethanol plus $\mathrm{CCl}_{4}$ pretreatment on the rat hepatic $\mathrm{NAD}^{+}$-dependent microsomal ALDH activity. Rats were treated with either ethanol alone (once, $5 \mathrm{~g} / \mathrm{kg}$, p.o.) and killed $18 \mathrm{hr}$ later, or $\mathrm{CCl}_{4}$ alone (once, $1 \mathrm{ml} / \mathrm{kg}$, i.p.) and killed $1 \mathrm{hr}$ later, or ethanol $\left(5 \mathrm{~g} / \mathrm{kg}\right.$, p.o.) followed $18 \mathrm{hr}$ later by $\mathrm{CCl}_{4}(1 \mathrm{ml} / \mathrm{kg}$, i.p.) and killed $1 \mathrm{hr}$ later. Control rats received vehicle only. Values represent mean \pm SEM for 4 rats. *Statistically significant $(P \leqslant 0.05)$ from appropriate control. ${ }^{* *}$ Statistically significant $(P \pm 0.05)$ from $\mathrm{CCl}_{4}$ treatment alone.

hepatic acetaldehyde and other toxic aldehyde generation and detoxication (Tottmar et al. 1973; Horton and Barrett, 1975), an examination of microsomal ALDH during $\mathrm{CCl}_{4}$ metabolism is viewed important. Our in vitro experiments reported earlier (Kenel and Kulkarni, 1985) indicated that rat hepatic microsomal and mitochondrial ALDH inhibition occurs concomitantly with $\mathrm{CCl}_{4}$ metabolism. In this paper, we present evidence for significant inhibition of membrane-bound ALDH activity in ethanol and $\mathrm{CCl}_{4}$ exposed rats.

\section{MATERIALS AND METHODS}

Amytal, pyrazole, deoxycholic acid, $\mathrm{NADP}^{+}, \mathrm{NADPH}$, $\mathrm{NAD}^{+} \mathrm{NADH}$, semicarbazide, and the reagents for the determination of serum glutamate pyruvate transaminase (SGPT) were obtained from Sigma Chemical Company, St Louis, MO. Thiourea was purchased from Alfa products, Danvers, Mass. Reagent grade acetaldehyde was obtained from Matheson, Coleman, and Bell of Norwood, Ohio. $\mathrm{CCl}_{4}$ was a Fisher product. One hundred percent ethanol was obtained from Aaper Alcohol and Chemical Co., Louisville, KY.

Male 200-250 g Sprague-Dawley rats (Charles River, Portage, MI) were housed two per cage and allowed free access to Purina Rat Chow and water. Rats were treated with either ethanol alone (once, $5 \mathrm{~g} / \mathrm{kg}, \mathrm{p} . \mathrm{o}$.) and killed $18 \mathrm{hr}$ later, or $\mathrm{CCl}_{4}$ alone (once, $1 \mathrm{ml} / \mathrm{kg}$, i.p.) and killed 1 or $24 \mathrm{hr}$ later, or ethanol $\left(5 \mathrm{~g} / \mathrm{kg}\right.$, p.o.) followed $18 \mathrm{hr}$ later by $\mathrm{CCl}_{4}$ ( $1 \mathrm{ml} / \mathrm{kg}$, i.p.) and killed 1 or $24 \mathrm{hr}$ later. Both control and treated animals were fasted for $8 \mathrm{hr}$ before the ethanol treatment to eliminate differences in food consumption. Ethanol and $\mathrm{CCl}_{4}$ were administered as $50 \%$ solutions in distilled water and corn oil, respectively. Control rats received equal volumes of vehicle only.
Animals were anesthetized with $\mathrm{CO}_{2}$ while blood was collected from the posterior vena cava for SGPT determination. Blood acetaldehyde levels were obtained with slight modification of the procedure described by Anderson et al. (1981). Blood sample $(3 \mathrm{ml})$ obtained by a heart puncture was placed in a $500 \mathrm{ml}$ Erlenmeyer flask containing $0.1 \mathrm{M}$ thiourea $(12 \mathrm{ml})$ dissolved in $0.1 \mathrm{~N} \mathrm{HCl}$. One milliliter of $0.15 \mathrm{M}$ semicarbazide in $0.2 \mathrm{M}$ sodium phosphate buffer, pH 7.0 was placed in a $10 \mathrm{ml}$ beaker. The semicarbazide containing beaker was lowered into the head space of the Erlenmeyer flask, and the latter was then sealed. After heating at $40^{\circ} \mathrm{C}$ for $18 \mathrm{hr}, 0.45 \mathrm{ml}$ of the acetaldehydesemicarbazide adduct was sealed in a $25 \mathrm{ml}$ reaction flask containing $100 \mu \mathrm{l}$ of concentrated $\mathrm{HCl}$. At this time $100 \mu$ l of a 1:10,000 dilution of isopropanol was added as an internal standard. The reaction flask was heated at $40^{\circ}$ for $90 \mathrm{~min}$. A $5 \mathrm{ml}$ head space sample was analyzed by gas chromatography for acetaldehyde content using a $(6 \mathrm{ft} \times 0.4 \mathrm{~mm}$ i.d.) column containing Poropak $\mathrm{Q}$. The Varian model 3700 gas chromatograph equipped with a flame ionization detector was operated under following conditions: carrier gas $20 \mathrm{ml} / \mathrm{min}$; inlet, column and detector temperature were $190^{\circ}, 150^{\circ}$, and $190^{\circ} \mathrm{C}$, respectively.

The washed liver subcellular fractions were prepared and assayed for total ALDH as described previously (Kenel and Kulkarni, 1985). The specific activity was corrected for protein recovery and is expressed as $\mathrm{mol} / \mathrm{min} / \mathrm{g}$ liver. SGPT assays were performed according to the manufacturer's instructions. Protein was determined according to the Biuret method as described by Gornall et al. (1949). Statistical analysis consisted of analysis of variance followed by Duncan's multiple range test. Significance was assumed at $P \leqslant 0.05$.

\section{RESULTS}

The effects of in vivo ethanol-CCl${ }_{4}$ administration to rats on in vitro $\mathrm{NAD}^{+}$-dependent liver microsomal ALDH are shown in Fig. 1. An $18 \mathrm{hr}$ exposure to ethanol alone did not significantly alter ALDH activity while $\mathrm{CCl}_{4}$ treatment after $1 \mathrm{hr}$ resulted in a $37 \%$ $(P \leqslant 0.05)$ loss. The animals receiving both treatments showed a $34 \%$ decline in ALDH activity which was not statistically different from $\mathrm{CCl}_{4}$ treatment alone. The blood levels of acetaldehyde, $1 \mathrm{hr}$ following $\mathrm{CCl}_{4}$ exposure in ethanol pretreated animals (Table 1) were not significantly elevated over ethanol alone treated animals.

Figures 2-4 show the effects of in vivo ethanol- $\mathrm{CCl}_{4}$ exposure on in vitro microsomal, mitochondrial, and cytosolic ALDH activities respectively, $24 \mathrm{hr}$ following $\mathrm{CCl}_{4}$ treatment. $\mathrm{NAD}^{+}$-dependent microsomal ALDH (Fig. 2) was significantly decreased $(52 \%)$ in animals exposed to $\mathrm{CCl}_{4}$ alone. Ethanol alone also caused an $11 \%$ loss in activity. Hepatotoxicity of $\mathrm{CCl}_{4}$ was potentiated by ethanol as indicated by SGPT values (Fig. 5), and in these animals an $81 \%$ decline in microsomal $\mathrm{NAD}^{+}$-dependent ALDH was

Table 1. Blood acetaldehyde levels in $\mathrm{CCl}_{4}$ and ethanol treated rats

\begin{tabular}{cccc}
\hline & \multicolumn{3}{c}{ Blood acetaldehyde $(\mathrm{nmol} / \mathrm{ml})$} \\
$\begin{array}{c}\text { Vehicle } \\
\text { Control }\end{array}$ & $\begin{array}{c}\mathrm{CCl}_{4} \\
\text { alone }\end{array}$ & $\begin{array}{c}\text { Ethanol } \\
\text { alone }\end{array}$ & Ethanol $+\mathrm{CCl}_{4}$ \\
\hline $23 \pm 6.3$ & $21 \pm 4.4$ & $35 \pm 5.2$ & $37 \pm 6.0$ \\
\hline
\end{tabular}

Rats were treated with either ethanol alone (once, $5 \mathrm{~g} / \mathrm{kg}, \mathrm{p} . \mathrm{o}$ ) and killed $18 \mathrm{hr}$ later, or $\mathrm{CCl}_{4}$ alone (once, $1 \mathrm{ml} / \mathrm{kg}$, i.p.) and killed $1 \mathrm{hr}$ later, or ethanol $\left(5 \mathrm{~g} / \mathrm{kg}, \mathrm{p} .0\right.$.) followed $18 \mathrm{hr}$ later by $\mathrm{CCl}_{4}$ ( $1 \mathrm{ml} / \mathrm{kg}$, i.p.) and killed $\mathrm{I} \mathrm{hr}$ later. Control rats received vehicle only. Each value represents mean \pm SEM for 4 rats. 


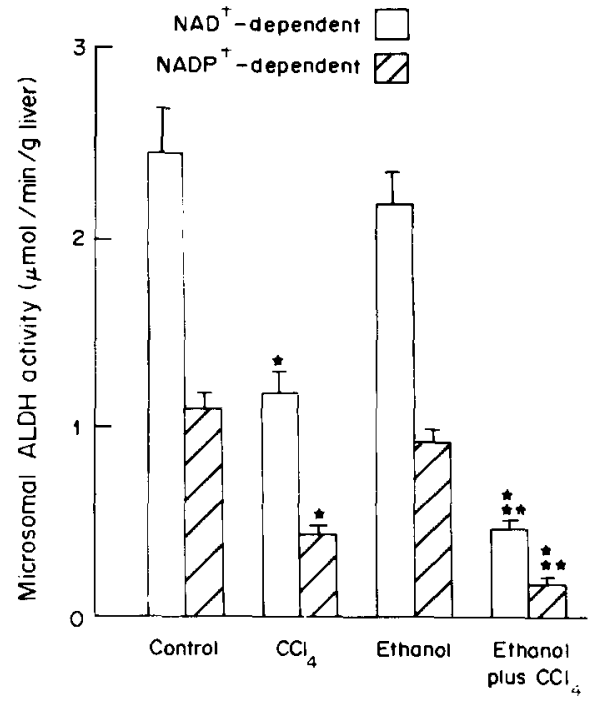

Fig. 2. Effect of $\mathrm{CCl}_{4}$, ethanol and ethanol plus $\mathrm{CCl}_{4}$ pretreatment on the rat hepatic microsomal ALDH activity. Rats were treated with either ethanol alone (once, $5 \mathrm{~g} / \mathrm{kg}$, p.o.) and killed $18 \mathrm{hr}$ later, or $\mathrm{CCl}_{4}$ alone (once, $1 \mathrm{ml} / \mathrm{kg}$, i.p.) and killed $24 \mathrm{hr}$ later, or ethanol $(5 \mathrm{~g} / \mathrm{kg}$, p.o. $)$ followed $18 \mathrm{hr}$ later by $\mathrm{CCl}_{4}(1 \mathrm{ml} / \mathrm{kg}$, i.p. $)$ and killed $24 \mathrm{hr}$ later. Control rats received vehicle only. Values represent the mean \pm SEM for 4 rats. *Statistically significant $(P<0.05)$ from appropriate control. ${ }^{* *}$ Statistically significant $(P \leqslant 0.05)$ from $\mathrm{CCl}_{4}$ treatment alone.

observed (Fig. 2). The $\mathrm{NAD}^{+}$-dependent mitochondrial ALDH (Fig. 3) declined $42 \%$ in $\mathrm{CCl}_{4}$ treated rats but remained essentially unchanged in ethanol treated animals. In ethanol $+\mathrm{CCl}_{4}$ treated rats the observed decline of $57 \%$ in $\mathrm{NAD}^{+}$-dependent mitochondrial ALDH was significantly different from $\mathrm{CCl}_{4}$ alone treated animals. Finally, ethanol treatment alone resulted in a non-significant decline $(5 \%)$ in $\mathrm{NAD}^{+}$-dependent cytosolic ALDH (Fig. 4). In ethanol- $\mathrm{CCl}_{4}$ treated animals the observed $48 \%$ decline in $\mathrm{NAD}^{+}$-dependent cytosolic ALDH, as compared to rats receiving corn oil only, was not significantly different from the decline of $40 \%$ due to $\mathrm{CCl}_{4}$ alone.

Essentially similar trends in inhibition of microsomal, mitochondrial, and cytosolic ALDH were observed for the $\mathrm{NADP}^{+}$-dependent activity (Figs 2, 3 and 4).

\section{DISCUSSION}

With dismissal of the recently advanced hypothesis based on alterations in cell calcium homeostasis (Recknagel, 1983), the question of which biochemical mechanism is responsible for $\mathrm{CCl}_{4}$ hepatotoxicity remains unanswered. Earlier our laboratory demonstrated that within $5 \mathrm{~min}$ the in vitro metabolism of $\mathrm{CCl}_{4}$ leads to a significant inhibition of rat microsmal and mitochondrial ALDH activity (Kenel and Kulkarni, 1985). Furthermore, literature reports have shown that lipid peroxidation initiated by $\mathrm{CCl}_{4}(\mathrm{Rao}$ and Recknagel, 1968) and covalent binding of ${ }^{14} \mathrm{C}$ from in vivo administered ${ }^{14} \mathrm{CCl}_{4}$ (Rao and Recknagel, 1969) are at or near maximum within $15 \mathrm{~min}$

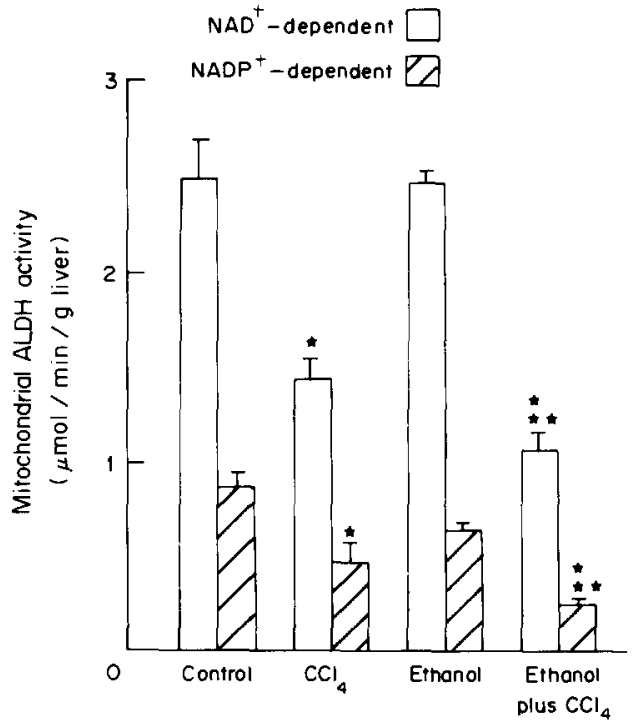

Fig. 3. Effect of $\mathrm{CCl}_{4}$, ethanol and ethanol plus $\mathrm{CCl}_{4}$ pretreatment on the rat hepatic mitochondrial ALDH activity. Rats were treated with either ethanol alone (once, $5 \mathrm{~g} / \mathrm{kg}, \mathrm{p.o}$.) and killed $18 \mathrm{hr}$ later, or $\mathrm{CCl}_{4}$ alone (once, $1 \mathrm{ml} / \mathrm{kg}$, i.p.) and killed $24 \mathrm{hr}$ later, or ethanol $(5 \mathrm{~g} / \mathrm{kg}, \mathrm{p.o}$.) followed $18 \mathrm{hr}$ later by $\mathrm{CCl}_{4}(1 \mathrm{ml} / \mathrm{kg}$, i.p. $)$ and killed $24 \mathrm{hr}$ later. Control rats received vehicle only. Values represent the mean $\pm S E M$ for 4 rats. *Statistically significant $(P \leqslant 0.05)$ from appropriate control. ${ }^{* *}$ Statistically significant $(P \leqslant 0.05)$ from $\mathrm{CCl}_{4}$ treatment alone.

of dosing. Therefore, an objective of this study was to determine if in vivo $\mathrm{CCl}_{4}$ exposure results in an inhibition of ALDH. It was proposed (Kenel and Kulkarni, 1985) that as a consequence, acetaldehyde

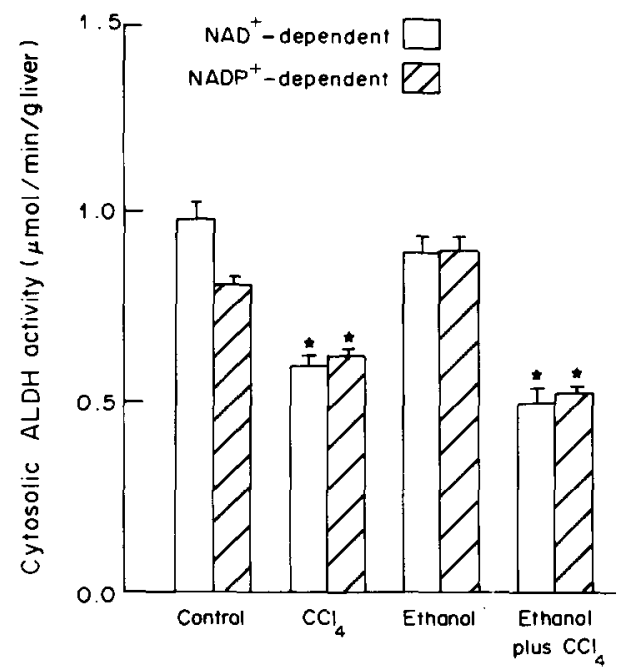

Fig. 4. Effect of $\mathrm{CCl}_{4}$, ethanol and ethanol plus $\mathrm{CCl}_{4}$ pretreatment on the rat hepatic cytosolic ALDH activity. Rats were treated with either ethanol alone (once, $5 \mathrm{~g} / \mathrm{kg}$, p.o.) and killed $18 \mathrm{hr}$ later, or $\mathrm{CCl}_{4}$ alone (once, $1 \mathrm{ml} / \mathrm{kg}$, i.p.) and killed $24 \mathrm{hr}$ later, or ethanol $(5 \mathrm{~g} / \mathrm{kg}$, p.o.) followed $18 \mathrm{hr}$ later by $\mathrm{CCl}_{4}(\mathrm{lml} / \mathrm{kg}$, i.p.) and killed $24 \mathrm{hr}$ later. Control rats received vehicle only. Values represent the mean SE for 4 rats. ${ }^{*}$ Statistically significant $(P \leqslant 0.05)$ from appropriate control. **Statistically significant $(P \leqslant 0.05)$ from $\mathrm{CCl}_{4}$ treatment alone. 


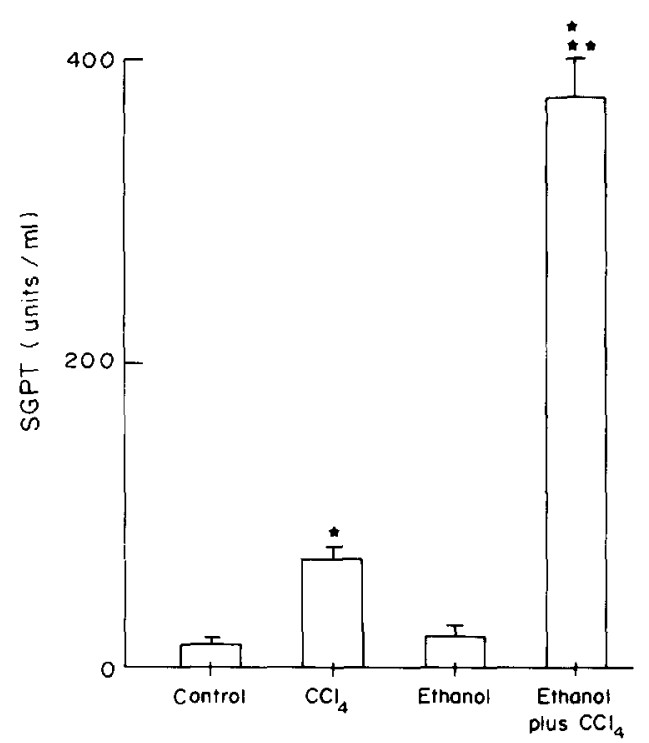

Fig. 5. Effect of $\mathrm{CCl}_{4}$, ethanol and ethanol plus $\mathrm{CCl}_{4}$ pretreatment on the rat hepatic serum SGPT values. Rats were treated with either ethanol alone (once, $5 \mathrm{~g} / \mathrm{kg}$, p.o.) and killed $18 \mathrm{hr}$ later, or $\mathrm{CCl}_{4}$ alone (once, $1 \mathrm{ml} / \mathrm{kg}$, i.p.) and killed $24 \mathrm{hr}$ later, or ethanol $(5 \mathrm{~g} / \mathrm{kg}$, p.o.) followed $18 \mathrm{hr}$ later by $\mathrm{CCl}_{4}(1 \mathrm{ml} / \mathrm{kg}$, i.p.) and killed $24 \mathrm{hr}$ later. Control rats received vehicle only. Values represent the mean $\pm S E M$ for 4 rats. *Statistically significant $(P \leqslant 0.05)$ from appropriate control. **Statistically significant $(P \leqslant 0.05)$ from $\mathrm{CCl}_{4}$ treatment alone.

and other cytotoxic aldehydes would accumulate in the hepatocytes and this may serve as a conceivable mechanism of ethanol potentiation of $\mathrm{CCl}_{4}$ hepatotoxicity. If the ALDH inhibition hypothesis is valid then inhibition should occur not only shortly after $\mathrm{CCl}_{4}$ poisoning, but be persistent and cumulative at the time of maximum hepatotoxicity. Therefore, ALDH activity was evaluated at 1 and $24 \mathrm{hr}$ following $\mathrm{CCl}_{4}$ expsosure in ethanol pretreated rats.

Microsomal ALDH was studied because, if an early cellular effect was to occur, it would most likely occur at the well accepted site of $\mathrm{CCl}_{4}$ metabolism, the endoplasmic reticulum. Our data in Figure 1 show that $1 \mathrm{hr}$ following $\mathrm{CCl}_{4}$ treatment there is a significant decline in microsomal ALDH activity. This suggests that at this stage of hepatotoxicity the observed inhibitory effects of $\mathrm{CCl}_{4}$ on $\mathrm{ALDH}$ are probably due to the biochemical events rather than the results of hepatocyte necrosis. In an earlier study on the time course of the $\mathrm{CCl}_{4}$-induced decrease in mitochondrial ALDH, Hjelle et al. (1983) reported no significant inhibition $2 \mathrm{hr}$ after exposure. However, a maximum depression of about $56 \%$ in ALDH activity was observed by $6 \mathrm{hr}$. The possible effects on the microsomal ALDH were not considered. In this study, a sequential exposure to ethanol and $\mathrm{CCl}_{4}$ was found to result in a significant inhibition of microsomal ALDH. However, the magnitude of inhibition was nearly equal to that observed in rats exposed to $\mathrm{CCl}_{4}$ alone (Fig. 1). This may be related to the protection rendered by various defense systems. At this early stage of $\mathrm{CCl}_{4}$ poisoning, the available content of reduced glutathione and other tissue anti- oxidants as well as ethanol induced glutathione reductase and glutathione peroxidase activities (MacDonald, 1973) apparently provide necessary partial protection.

Our data on the alteration of microsomal and mitochondrial ALDH $24 \mathrm{hr}$ after $\mathrm{CCl}_{4}$ exposure differ considerably from those reported by $\mathrm{Hjelle}$ et al. (1981). In contrast to the significant inhibition noted in our study, these authors did not observe any inhibition of microsomal and mitochondrial total ALDH. Only mitochondrial low $K_{\mathrm{m}}$ ALDH activity towards formaldehyde was reported to be decreased by $43-46 \%$. This descrepancy in the results can partly be explained by the differences in the methodology used. Hjelle et al. (1981) neither incorporated into assay medium rotenone which is necessary to block mitochondrial NADH oxidase (Tottmar et al., 1973) nor used detergent to release latent ALDH activity (Horton and Barrett, 1975). Furthermore, the assays were performed at $7.4 \mathrm{pH}$ even though the reported optimum pH for ALDH is 8.8 (Tottmar et al., 1973; Horton and Barrett, 1975). As a result of the suboptimal assay conditions employed the total ALDH activities noted by Hjelle et al. (1981) for the hepatic microsomes and mitochondria from control rats appear to be about 3 to 7 fold lower than those reported in the literature (Tottmar et al., 1973; Horton and Barrett, 1975) or observed in our studies. In any case, the ethanol $+\mathrm{CCl}_{4}$ treated animals sacrificed $24 \mathrm{hr}$ following $\mathrm{CCl}_{4}$ exposure exhibited a significantly greater inhibition of microsomal and mitochondrial ALDH than the $\mathrm{CCl}_{4}$ treated animals (Figs 2 and 3). Apparently, increased rate of in vivo $\mathrm{CCl}_{4}$ metabolism due to induction of microsomal cytochrome $P-450$ in the ethanol pretreated animals (Sato et al., 1981) results in increased $\mathrm{CCl}_{4}$-stimulated lipid peroxidation and/or covalent binding of free radical intermediates that overwhelm the cellular defenses and ultimately leads to a drastic decline in the activity of membrane bound ALDH. Since the animals were sacrificed at a time ( $24 \mathrm{hr}$ following $\mathrm{CCl}_{4}$ treatment) when hepatotoxicity is maximally expressed, the observed decline in ALDH may be due to cellular necrosis and/or due to cumulative ALDH inhibition in dying hepatocytes resulting from subsequent passes of $\mathrm{CCl}_{4}$ through the hepatic tissue.

Since the blood acetaldehyde levels observed (Table 1) in ethanol and $\mathrm{CCl}_{4}$ exposed rats were not elevated at $1 \mathrm{hr}$, it appears that both ethanol and acetaldehyde were largely eliminated prior to $\mathrm{CCl}_{4}$ treatment or that the remaining ALDH activity and possibly other enzymes were sufficient to metabolize any acetaldehyde being generated at that time. However, it should be pointed out that how well blood levels reflect acetaldehyde contents of hepatocytes is unknown. It is, therefore, conceivable that localized levels of acetaldehyde and other cytotoxic aldehydes may reach toxic levels within mitochondria and the endoplasmic reticulum. In view of the observed ALDH inhibition a significant accumulation of one or more cytotoxic aldehydic products of lipid peroxidation could occur in the early stages of ethanol- $\mathrm{CCl}_{4}$ toxicity. These toxic aldehydes, besides inhibiting ALDH, may play some contributory role in the genesis of enhanced $\mathrm{CCl}_{4}$ hepatotoxicity. In conclusion, our data suggest that in vivo inhibition 
of membrane bound ALDH may represent one of the major mechanisms responsible for $\mathrm{CCl}_{4}$ hepatotoxicity and its potentiation by ethanol pretreatment. This hypothesis, however, does not exclude the involvement of other contributory factors reported by other investigators (Recknagel, 1983; Smith et al., 1983). Which ultimate toxicant(s) is (are) involved in the observed ethanol potentiation of $\mathrm{CCl}_{4}$ hepatotoxicity remains to be determined.

\section{SUMMARY}

Recently Recknagel (1983) concluded that none of the previously proposed biochemical mechanisms of action satisfactorily explains genesis of $\mathrm{CCl}_{4}$ hepatotoxicity. In our in vitro studies (Kenel and Kulkarni, 1985) we observed a significant inhibition of membrane-bound ALDH occurring concomitantly with $\mathrm{CCl}_{4}$ bioactivation. Both covalent binding and lipid peroxidation were found to contribute to the inhibitory process. We have extended these observations and now demonstrate a significant in vivo inhibition of hepatic membrane-bound ALDH during early as well as acute stages of hepatotoxocity in $\mathrm{CCl}_{4}$ or $\mathrm{CCl}_{4}$ plus ethanol treated rats. It is proposed that in vivo $\mathrm{ALDH}$ inhibition may be the early event that links $\mathrm{CCl}_{4}$ metabolism to the reported cascade of biochemical lesions leading to hepatotoxicity. Although the involvement of cytotoxic aldehydes other than acetaldehyde is most likely, further studies are needed to identify the ultimate toxicant(s) and its biochemical mechanism of action.

Acknowledgements - This work was supported in part by the grant T32 ES07062 from the U.S. Public Health Service, National Institute of Environmental Health Sciences.

\section{REFERENCES}

Anderson R. A., Brentzel H. J. and Thurman R. G. (1981) Determination of micromolar levels of acetaldehyde in biological preparations. Adv. exp. Biol. Med. 32, 315-311.

Benedetti A., Comporti M. and Esterbauer H. (1980) Identification of 4-hydroxynonenal as a cytotoxic product originating from the peroxidation of liver microsomal lipids. Biochim. biophys. Acta 620, 281-296.

Benedetti A., Comporti H., Fulceri R. and Esterbauer H. (1984) Cytotoxic aldehydes originating from the lipid peroxidation of liver microsomal lipids. Identification of 4,5-dihydroxydecenal. Biochim. biophy. Acta 792, $172-181$.

Benedetti A., Esterbauer H., Ferrali M., Fulceri R. and Comporti M. (1982) Evidence for aldehydes bound to liver microsomal protein following $\mathrm{CCl}_{4}$ or $\mathrm{BrCCl}_{3}$ poisoning. Biochim. biophys. Acta 711, 345.

Bird R. P., Draper H. H. and Valli V. E. O. (1982) Toxicological evaluation of malonaldehyde: A 12 month study in mice. J. tox. envir. Hlth 10, 897-905.

Cantillena L. R., Cagen S. Z. and Klaassen C. D. (1979) Methanol potentiation of carbon tetrachloride induced hepatotoxicity. Proc. Soc. exp. Biol. Med. 162, 29-95.

Chio K. S. and Tappel A. L. (1969) Inactivation of ribonuclease and other enzymes by peroxidizing lipids and by malonaldehyde. Biochemistry 8, 2827-2832.

Cornish H. H. and Adefuin J. (1967) Potentiation of carbon tetrachloride toxicity by aliphatic alcohols. Arch. Envir. Health 14, 447-449.

Curtis L. R. and Mehendale H. M. (1980) Specificity of chlordecone-induced potentiation of carbon tetrachloride hepatotoxicity. Drug Metab. Dispos. 8, 23-27.
Dianzani M. U. (1982) Biochemical effects of saturated and unsaturated aldehydes. In Free Radicals, Lipid Peroxidation, and Cancer (Edited by McBrien D. C. H. and Slater T. F.), pp. 129-158. Academic Press, London.

Dietz F. K. and Traiger G. J. (1979) Potentiation of $\mathrm{CCl}_{4}$ hepatotoxicity in rats by a metabolite of 2-butanone: 2,3-butanediol. Toxicology 14, 209-215.

Gornall A. G., Bardawill C. J. and David M. M. (1949) Determination of serum proteins by means of the biuret reaction. J. biol. Chem. 177, 751-760.

Hewitt W. R. and Plaa G. L. (1979) Potentiation of carbon tetrachloride-induced hepatotoxicity by 1,3-butanediol. Toxic. appl. Pharmac. 47, 177-180.

Hjelle J. J. and Petersen D. R. (1981) Decreased in vivo acetaldehyde oxidation and hepatic aldehyde dehydrogenase inhibition in $\mathrm{C}_{57} \mathrm{BL}$ and DBA mice treated with carbon tetrachloride. Toxic. appl. Pharmac. 59, 15-24.

Hjelle J. J., Grubbs J. H. and Petersen D. R. (1981) Inhibition of rat liver aldehyde dehydrogenase by carbon tetrachloride. J. Pharmac. exp. Ther. 219, 821-826.

Hjelle J. J., Grubbs J. H., Beer D. G. and Petersen D. R. (1983) Time course of the carbon tetrachloride-induced decrease in mitochondrial aldehyde dehydrogenase activity. Toxic. appl. Pharmac. 67, 159-165.

Horton A. A. and Barrett M. C. (1975) The subcellular localization of aldehyde dehydrogenase in rat liver. Archs Biochem. Biophys. 167, 426-436.

Kenel M. F. and Kulkarni A. P. (1985) Inhibition of hepatic aldehyde dehydrogenase by carbon tetrachloride: an in vitro study. Int. J. Biochem. 17, 605-610.

Lieber C. S. (1980) Alcohol, protein metabolism, and liver injury. Gastroenterology 79, 373-390.

Lieber C. S., Baraona E., Matsuda Y., Salaspuro M., Hasumura Y. and Matsuzaki S. (1981) Hepatotoxicity of acetaldehyde. Adv. exp. Med. Biol. 126, 397-411.

MacDonald C. M. (1973) The effects of ethanol on hepatic lipid peroxidation and on the activities of glutathione reductase and peroxidase. FEBS Lett. 35, 227-230.

Muller A. and Sies H. (1982) Role of alcohol dehydrogenase activity and of acetaldehyde in ethanol induced ethane and pentane production by isolated perfused rat liver. Biochem. J. 206, 153-156.

Rao K. S. and Recknagel R. O. (1968) Early onset of lipoperoxidation in rat liver after carbon tetrachloride administration. Exp. Mol. Path. 9, 271-278.

Rao K. S. and Recknagel R. O. (1969) Early incorporation of carbon-labeled carbon tetrachloride into rat liver particulate lipids and proteins. Exp. Mol. Path. 10, 219-228.

Recknagel R. O. (1983) A new direction in the study of carbon tetrachloride hepatotoxidity. Life Sci. 33, 401-408.

Sato A., Nakajima T. and Koyama Y. (1981) Dose-related effects of a single dose of ethanol on the metabolism in rat liver of some aromatic and chlorinated hydrocarbons. Toxic. appl. Pharmac. 60, 8-15.

Smith M. T., Thor H. and Orrenius S. (1983) The role of lipid peroxidation in the toxicity of foreign compounds to liver cells. Biochem. Pharmac. 32, 763-764.

Stege T. E. (1982) Acetaldehyde induced lipid peroxidation in isolated hepatocytes. Res. commun. Chem. Pathol. Pharmac. 36, 287-297.

Strubelt O., Siegers C. P. and Breining H. (1974) Comparative study of the absorption, elimination, and acute hepatotoxic action of ethanol in guinea pigs and rats. Arch. Toxicol. 32, 83-95.

Tottmar S. O. C., Pettersson H. and Kiessling K. H. (1973) The subcellular distribution and properties of aldehyde dehydrogenases in rat liver. Biochem. $J .135,577-586$.

Traiger G. J. and Bruckner J. V. (1976) The participation of 2-butanone in 2-butanol-induced potentiation of carbon tetrachloride hepatotoxicity. J. Pharmac. exp. Ther. 196, 493-500.

Traiger G. J. and Plaa G. L. (1971) Differences in the 
potentiation of carbon tetrachloride hepatotoxicity in rats by ethanol and isopropanol pretreatment. Toxic. appl. Pharmac. 20, 105-112

Traiger G. J. and Plaa G. L. (1972) Relationship of alcohol metabolism to the potentiation of $\mathrm{CCl}_{4}$ hepatotoxicity of alcohol metabolism to the potentiation of $\mathrm{CCl}_{4}$ hepatotoxicity induced by aliphatic alcohols. J. Pharmac. exp. Ther. 183, 481-488.

Traiger G. J. and Plaa G. L. (1973) Effect of aminotriazole on isopropanol- and acetone-induced potentiation of $\mathrm{CCl}_{4}$ hepatotoxicity. Can J. Physiol. Pharmac. 51, 291-296.
Traiger G. J. and Plaa G. L. (1974) Chlorinated hydrocarbon toxicity: Potentiation by isopropanol and acetone. Archs envir. Health 28, 276-278.

Ugazio G., Torrielli M. V., Burdino E., Sawyer B. C. and Slater T. F. (1976) Long range effects of products of carbon tetrachloride-stimulated lipid peroxidation. Biochem. Soc. Trans. 4, 353-356.

Valenzuela A., Fernandez N., Fernandez V., Ugarte G. and Videla L. A. (1980) Effect of acute ethanol ingestion on lipoperoxidation and on the activity of the enzymes related to peroxide metabolism in rat liver. FEBS Lett. 111, 11-13. 